\title{
Development and improvement of lost foam casting technology based on mathematical modeling
}

\author{
Nikolay Nesterov ${ }^{1, *}$, and Boris Vorontsov ${ }^{1}$ \\ ${ }^{1}$ Kurgan State University, Russia
}

\begin{abstract}
A detailed analysis of the process of filling the mould for lost foam casting technology was made based on a mathematical model, that takes into account the emergence of low-frequency oscillations. The optimum range of technological parameters for a few specific details were discovered. The factors that may lead to the release of metal and to mould collapse were also identified.
\end{abstract}

The present work is devoted to the issues of determining the optimal filling of the mould in lost foam casting, using developed mathematical models. This method of casting is one of the most modern methods to obtain precise workpieces. To date is known for a number of mathematical models of this process using the analytical method or software [1- 7].

To identify necessary when designing technological processes, patterns and indicators previously developed mathematical models of the kinetics of mould filling and lowfrequency oscillations in the mould [5-7]. The schema for process of mould filling is shown in Figure 1.

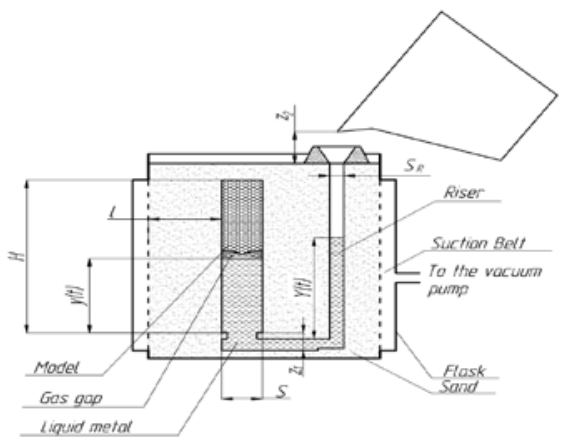

Fig. 1. The schema for process of mould filling in lost foam custing.

Using mathematical models $[6,7]$ expression for the level of the liquid metal in the mould $y_{1}(t)$ of metal level in riser $Y_{1}(t)$ can be represented as follows:

${ }^{*}$ Corresponding author: nesterovnv@,rambler.ru 


$$
\begin{gathered}
Y_{1}(t)=\left\{\begin{array}{l}
Y(t) \text { if } t \leq t_{2} ; \\
Y(t)+\frac{q \mu t_{1}}{S_{R}} \sqrt{\frac{2}{\gamma(\gamma-1)}} e^{-\beta t} \sin \left(\sqrt{\omega^{2}-\beta^{2}} \cdot t\right) \quad \text { if } t>t_{2}
\end{array}\right. \\
y_{1}(t)=\left\{\begin{array}{l}
y(t) \text { if } t \leq t_{2} ; \\
y(t)+\frac{q \mu t_{1}}{S} \sqrt{\frac{2}{\gamma(\gamma-1)}} e^{-\beta t} \sin \left(\sqrt{\omega^{2}-\beta^{2}} \cdot t\right) \text { if } t>t_{2}
\end{array},\right.
\end{gathered}
$$

where $y$ and $Y$-based on mathematical models [5] levels of liquid metal in the mould and in the riser without account of fluctuations; $q$-feeding speed of liquid metal from the ladle; $\mu$-hydraulic factor; $t 1$ the time of-formation gas space between liquid metal and the surface of polystyrene, [7]; $t 2$ - the time of filling in the bottom part of the gating system $z_{1}$ in Fig. $1 ; \gamma$-average Poisson's coefficient for polystyrene expanded products; $\beta$ Oscillation damping factor [7]; $\omega$-natural frequency of low-frequency fluctuations in metal [6].

Metal levels as f functions of time calculated on the base of mathematical models [5-7], are presented in Fig. 2. The process of mould filling in lost foam casting consists of several stages. Initially, the gas space generation between liquid metal and foam polystyrene models takes place (fig. 1), in which polystyrene thermally destructs in deficit of oxygen. Then simple molecular gases, gaseous hydrocarbons and aromatic hydrocarbons are formed. The gas amount generated side walls bordering the fireproof paint. Through them goes a stream of gaseous and vaporous products in space of flask, surrounding model, which is filled with sand. Gas formation period ends at the point (fig. 2), when leveling pressure in flask by changing the height of that gas space and the difference of metallostatic pressure in riser and form.

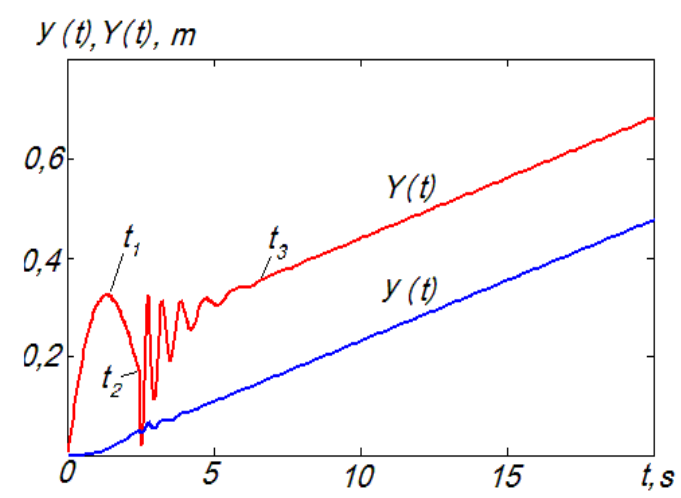

Fig. 2. The height of metal in riser and in the form as a function of time. The calculation is made for carbon steel. The height of cast is $430 \mathrm{~mm}$, means value of horizontal section $200 \mathrm{~mm} \times 100 \mathrm{~mm}$, riser height $640 \mathrm{~mm}$. The metal outlay from scoop is $1,1^{*} 10^{-3} \mathrm{~m}^{3} / \mathrm{s}$.

Until that point, virtually no form is filling, and the level of the liquid metal in the risergrow is up to some maximum, determined by the condition

$$
\frac{d}{d t} Y(t)=0
$$


Then starts filling with liquid metal sprues near the bottom of castings gained by this time in the riser. This process continues until the liquid metal fills the lower part of the gating system and mould and stops interacting with the span gas atmosphere-point $t_{2}$ (fig. 2 ). This reduces the level of metal strut and, consequently, reduces pressure in the gas gap between polystyrene and liquid metal. After completing this stage, parallel increasing the level of metal in riser and in mould starts.

The gas gap has rigidity. Therefore, this gas gap, together with the liquid metal in the form and in the riser forms elastic oscillating system. This system gets a boost from the metal, coming out from riser in the form, that interacts with the gas gap and starts lowfrequency vibrations, which manifest as fluctuations of metal level in the riser. These vibrations damp if metal entering speed is not changed and new impulses are not created. Attenuation occurs because the steam-gas products and liquid metal have viscosity.

After the attenuation of low-frequency oscillations of metal in the riser at the time $t_{3}$ the next filling of the form is going smoothly. Rising levels of metal in the form of lagging are behind growth levels of the metal in the riser, and the difference between them creates pressure in the gas gap.

The most important in terms of sustainability of mould is the third stage, where there are fluctuations of metal level in riser and the pressure in the volume of gas. If the amplitude is large, can occur two destructive processes (fig.3):

-release the liquid metal from riser at the moment $Y(t)>H$, after which "exposes" gas gap and pressure drops in it, since it would connect with the atmosphere;

-pressure drop in the gas gap on the the negative wave of oscillations.

In both cases, with large probability, flask's collapse happens and the casting will not work. It is because the pressure in the gas gap at some point will be low and will not deduct the wall shapes. If the pressure increase further "sand boil" happens, and it completes the destruction of the mould.

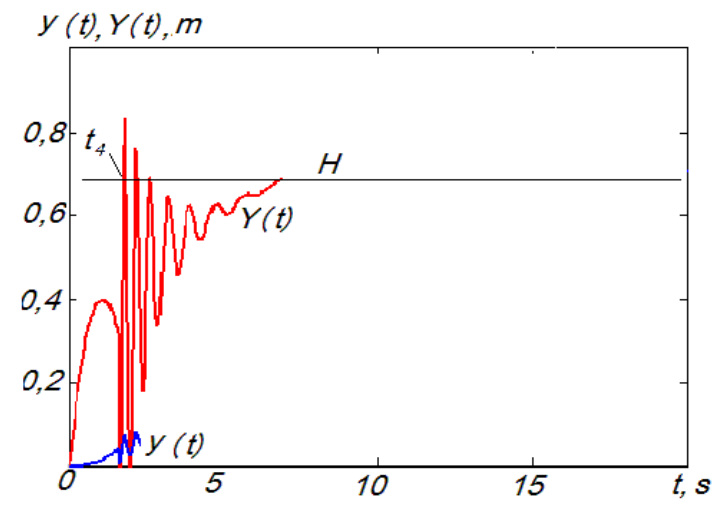

Fig. 3. The dynamics of fluctuations with a large amplitude in the riser and in mould, leading to the release of metal from the riser and the collapse of the mould. Data for calculation are the same as those in Fig.2.

Also mould collapse can occur if intake of liquid metal in the riser is insufficient, fig. 4. Consequently, at some point $t_{5}$, all the metal of riser enters the mould, because in it created a vacuum, and pressure in the gas gap falls to zero. In this case metal fluctuations in the mould do not arise. 


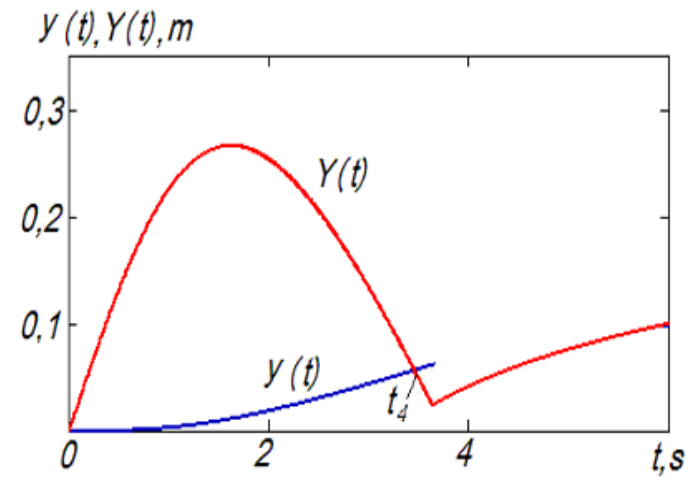

Fig. 4. The estimated temporal changes of levels of metal, explaining the collapse of the mould due to the small income of the metal in the riser. The flow of metal from the ladle $0,6^{*} 10^{-3} \mathrm{~m}^{3} / \mathrm{s}$. Data for calculation are the same as those in Fig.2.

Our studies permit to calculate technological parameters of the mould filling, when the collapse doesn't occur. Calculations were made based on the programme for 12-Matkad using mathematical models [5 - 7].

Using the calculated parameters experimental work was been to fill some detailsrepresentatives, specified in table 1. The experiment was carried out in Foundry enterprise "SOLNESS-METAL" in Krasnokamsk, Permskiy Krai. Photos of those castings produced by holding skilled works, are shown in table 1 . The fill was made through the riser with a diameter of $50 \mathrm{~mm}$ and a height of $0.7 \mathrm{~m}$.

Table 1. Calculated parameters of technological process used for manufacture of few steel casts.

\begin{tabular}{|c|c|c|c|c|}
\hline $\begin{array}{c}\text { The name of details- } \\
\text { representatives }\end{array}$ & $\begin{array}{c}\text { Fly-wheel } \\
\text { M200 }\end{array}$ & $\begin{array}{c}\text { Valve body } \\
\text { for gas } \\
\text { pipeline }\end{array}$ & $\begin{array}{c}\text { tee pipeline } \\
65 \times 21\end{array}$ & $\begin{array}{c}\text { d-pad } \\
\text { for the } \\
\text { pipeline } \\
65 \times 21\end{array}$ \\
\hline $\begin{array}{c}\text { Photo of } \\
\text { details-representatives }\end{array}$ & Diam. & $300 \times 180 \times 216$ & $366 \times 288 \times 199$ & $541 \times 380 \times 406$ \\
\hline dimensions, mm & $200 \times 16$ & 19,6 & 40,8 & 128,0 \\
\hline mass, $\mathrm{kg}$ & 30 & 2 & 2 & 1 \\
\hline Number of casts in mould & 1,1 & 1,0 & 1,1 & 1,2 \\
\hline $\begin{array}{c}\text { Speed of metal feed in the } \\
\text { form, } 10^{-3} \mathrm{~m}^{3} / \mathrm{s}\end{array}$ & 21,5 & 31 & 30 & 60 \\
\hline Calculated time of filling, $\mathrm{s}$ & 23 & 29 & 31 & 58 \\
\hline $\begin{array}{c}\text { Real time of filling, } \mathrm{s} \\
\text { Pa3peжeние в onокe, } 10^{4} \mathrm{~Pa}\end{array}$ & $-4,5$ & $-4,5$ & $-6,0$ & $-5,0$ \\
\hline $\begin{array}{c}\text { The form gas-penetration } \\
\mathrm{m}^{4} / \mathrm{N}^{*} \mathrm{~s}\end{array}$ & $8,5 \times 10^{-7}$ & $8,5 \times 10^{-7}$ & $8,5 \times 10^{-7}$ & $8,5 \times 10^{-7}$ \\
\hline Temperature of filling, $\mathrm{K}$ & 1890 & 1870 & 1870 & 1870 \\
\hline $\begin{array}{c}\text { Distance from model to } \\
\text { zone of vacuum in flask, } \mathrm{m}\end{array}$ & 0,35 & 0,25 & 0,2 & 0,15 \\
\hline
\end{tabular}


Thus, carried out by means of the developed mathematical models of calculation parameters filling form when molding on gasified models have demonstrated their reliability and ability to use for development and improving the technology.

\section{Conclusions}

1. The analysis of mathematical models of form filling when lost foam castings shows, that this process involves the formation of gas gap between the liquid metal and foam polystyrene models, overlapping the connection of gas gap with atmosphere, the emergence and damping of metal low-frequency oscillations in the mould and in the riser, smooth filling of the form.

2. When submitting inflated the liquid metal into the mould, amplitude low-frequency oscillations of metal increases sharply, and the metal release out of the riser and the subsequent collapse of the mould due to the pressure drop in the gas gap tares place. Low speed of metal feed leads to the decreasing of the metal level in riser, and also crumbles the mould.

3. Mathematical models allow you to compute the optimal parameters to design technology for stable filling out a form with the lost foam casting.

4. Skilled work for pouring the castings made of steel, with estimated parameters of the technological process, has shown the ability to apply mathematical models to design the optimal casting technology on gasified models.

\section{References}

1. V.S. Shuliak, S.A. Rybakov, K.A. Grigrian. Proisvodstvo otlivok po gasifitsiruemym modeliam [The production of lost foam casting]. Moscow: MGIU, 2001. (In Russ).

2. S.H. Mirbagheri, H. Ashuri, N. Varahram, P. Davami. Simulation of mould filling in lost foam casting process. // International Journal of Cast Metals Research. Vol.16. Issue 6. pp. 554-565 (2003)

3. X.J. Liu, S.H. Bhavnani, R.A. Overfelt. Simulation of EPS foam decomposition in the lost foam casting process // Journal of Materials Processing Technology. Vol.182. Issues 1-3. pp. 333-342 (2007)

4. S.M.H. Mirbagheri, R. Babay, M. Dadashzadeh, M.T. Ahmadian and P. Davami. Simulation of Mold Filling in the EPC Process // Scientia Iranica. Vol. 11. Nos.1\&2. pp. 69-80 (2004)

5. N.V. Nesterov, A.G. Ermilov. Mathematical model of kinetics of filling the model during casting by gasified models // Russian Journal of Non Ferrous Metals. 2012. Vol. 53. No. 2. pp. 150-154 (2012)

6. N.V. Nesterov, A.G. Ermilov. Low Frequency Pulsations of the Melt during the Lost Foam Casting Process: Part 1 // Russian Journal of Non Ferrous Metals. Vol. 52. No. 6. pp. 499-503 (2011)

7. N.V. Nesterov., A.G. Ermilov. Low Frequency Pulsations of the Melt during the Lost Foam Casting Process: Part 2 // Russian Journal of Non Ferrous Metals. Vol. 53. No. 2. pp. 150-154 (2012) 